\title{
Impact of Surgical Training on Incidence of Surgical Site Infection
}

\author{
Rachel Rosenthal - Walter P. Weber - Marcel Zwahlen • \\ Heidi Misteli · Stefan Reck · Daniel Oertli • \\ Andreas F. Widmer · Walter R. Marti
}

Published online: 12 April 2009

(C) Société Internationale de Chirurgie 2009

\begin{abstract}
Background Despite availability of other training forms, tutorial assistance cannot be entirely replaced in surgical education. Concerns exist that tutorial assistance may lead to an increased rate of surgical site infection (SSI). The purpose of the present study was to investigate whether the risk of SSI is higher after surgery with tutorial assistance than after surgery performed autonomously by a fully trained surgeon.

Methods All consecutive visceral, vascular, and traumatological inpatient procedures at a Swiss University Hospital were prospectively recorded during a 24-month period, and the patients were followed for 12 months to ascertain the occurrence of SSI. Using univariable and multivariable logistic regressions, we assessed the association of tutorial assistance surgery with SSI in 6,103 interventions.

Results Autonomously performed surgery was associated with SSI in univariable analysis $(5.36 \%$ SSI vs. $3.81 \%$ for tutorial assistance, $p=0.006$ ). In multivariable analysis, the odds of SSI for tutorial assistance was no longer
\end{abstract}

R. Rosenthal · W. P. Weber · H. Misteli - S. Reck · D. Oertli · W. R. Marti ( $\square)$

Department of Surgery, Basel University Hospital, 4031, Basel,

Switzerland

e-mail:wrmarti@uhbs.ch

A. F. Widmer

Division of Infectious Diseases and Hospital Epidemiology, Basel University Hospital, 4031, Basel, Switzerland

M. Zwahlen

Research Support Unit, Institute of Social and Preventive Medicine, University of Bern, Hochschulstrasse 4, 3012, Bern, Switzerland significantly lower (Odds Ratio $[\mathrm{OR}]=0.82$; $95 \%$ Confidence Interval $[\mathrm{CI}]$ : $0.62-1.09 ; p=0.163)$.

Conclusions Surgical training does not lead to higher SSI rate if trainees are adequately supervised and interventions are carefully selected. Although other forms of training are useful, tutorial assistance in the operating room continues to be the mainstay of surgical education.

\section{Introduction}

Traditionally, surgical skills are acquired primarily in the operating room, first by observing and then by taking an increasingly active role in the procedure, pursuant to William Halsted's apprenticeship model ("see one, do one, teach one") [1]. The use of animal models is criticized by animal-rights organizations. Ethical, economic, and educational considerations have recently led to the development of alternative methods for teaching surgical techniques, such as box model or virtual reality (VR) simulation [2]. Virtual reality appears to be an ideal tool for training physicians in laparoscopic surgical skills. The interface between trainee and surgical site consisting of a video screen and instruments can readily be simulated by modern VR simulation technology. One major advantage of the VR simulator lies in its ability to serve not only as a training tool but also as a precise and objective assessment tool. Nevertheless, tutorial assistance during actual surgery continues to be necessary if the trainee is to acquire full command of surgical skills. This training system can only be justified, however, if it involves no rise in the complication rate. Because one of the most common postoperative complications is surgical site infection (SSI), the SSI rate is used here as one possible indicator 
of the overall complication rate associated with surgical training.

The purpose of the present study was to investigate the hypothesis that tutorial training in the operating room does not lead to a higher incidence of SSI than that recorded in surgery performed autonomously by board-certified surgeons.

\section{Materials and methods}

\section{Patients}

The incidence of SSI in all the visceral, vascular, and traumatological operations performed between 1 January 2000 and 31 December 2001 on inpatients at Basel University Hospital, Switzerland, was prospectively recorded. Outpatient surgery was excluded.

\section{Surgery}

An associate professor or senior board-certified fellow determined which procedures would be conducted under tutorial assistance in accordance with the following criteria: the assessment of patient comorbidity, the complexity of the intervention, and the trainee's operating experience. Complex interventions and surgery involving polymorbid patients were performed by a senior fellow, an associate professor, or the department head.

Operations were classified into one of two groups: tutorial assistance or autonomous interventions performed by a board-certified surgeon. Tutorial assistance was defined to be surgery performed by a resident assisted by a board-certified surgeon, or operations conducted by a general surgery fellow, supervised by a board-certified surgeon with extensive expertise in a field in which the lead surgeon was less experienced; an example of the latter might be a board-certified surgeon performing a vascular intervention assisted by a board-certified vascular surgeon.

The standard operation procedure in the operating room $(\mathrm{OR})$ requires a three-step desinfection around the incision area before sterile drapes are placed on the patient. The standard for desinfection was Betaseptic (Mundipharma, Basel, Switzerland), a solution of $4 \%$ povidone-iodine $(\mathrm{w} / \mathrm{v})$ and $96 \%$ alcohol $(\mathrm{w} / \mathrm{v})$ (active ingredients: iodine $3,2 \mathrm{~g}$ as povidone-iodine, $389 \mathrm{~g}$ 2-propanol $(49.5 \% \mathrm{v} / \mathrm{v})$ and $389 \mathrm{~g}$ ethanol $(46.2 \% \mathrm{v} / \mathrm{v})$ per $100 \mathrm{ml})$; Braunoderm (Braun Medical, Melsungen, Gemany), a solution of $1 \%$ povidone-iodine (w/v) in 50\% 2-propanol (w/v), and water (active ingredients: $0.9 \mathrm{~g}$ as povidone-iodine, $45.75 \mathrm{~g}$ 2-propanol $(58.2 \% \mathrm{v} / \mathrm{v})$ per $100 \mathrm{ml}$; further ingredients: sodium hydrogen phosphate dihydrate, potassium iodide, and purified water); and Braunol (Braun Medical,
Melsungen, Gemany), a solution of $7.5 \%$ povidone-iodine (w/v) and water (active ingredient: $7.5 \mathrm{~g}$ povidone-iodine; further ingredients: sodium hydrogen phosphate dehydrate, sodium iodate, macrogol laurylether-9 EO, sodium hydroxide, and purified water).

In case of allergies, Octenisept-a European product not licensed in the United States, but with a spectrum of antimicrobial activity similar to that of chlorhexidine-was used. This practice follows the World Health Organization (WHO) guideline; one of the authors is part of the Task Force on Patient Safety in Surgery. The guideline is now published in part, and was officially presented in June 2008 in Washington, DC.

Routine antibiotic prophylaxis for elective and emergency surgery consisted of a $1.5-\mathrm{g}$ single shot of cefuroxime for class II (clean-contaminated) and class III (contaminated) wounds [3-6], as well as for class I (clean) wounds where surgery entailed implanting a foreign body. A 500-mg dose of metronidazole was added in colorectal surgery. In procedures with a duration longer than $4 \mathrm{~h}$, a second dose of these antibiotics was administered, pursuant to hospital guidelines. Doses were adapted for patients with impaired renal function. Antibiotic prophylaxis was extended for $24 \mathrm{~h}$ after the intervention in osteosynthesis patients, who received $0.75 \mathrm{~g}$ of cefuroxim after 8 and $16 \mathrm{~h}$. In case of class I wounds without implanting a foreign body, no antibiotics were administered. Patients with class IV (dirty-infected) wounds were either treated with antibiotics in lieu of antimicrobial prophylaxis or, in the event of simple superficial abscess incisions, received no antibiotics at all.

\section{Surgical site infection}

Further to Centers for Disease Control and Prevention criteria [5, 6], surgical site infections occurring within 30 days of an operation involving no implant or within one year otherwise were prospectively recorded and classified as superficial incisional, deep incisional, or organ/space SSIs.

\section{Data acquisition}

Data on SSI risk factors were prospectively collected (Table 1). The lead anesthesiologist prospectively recorded the American Society of Anesthesiologists (ASA) classification, height, body weight, operating time, and the administration of antimicrobial prophylaxis, whereas the surgeon prospectively recorded wound classification. Immediately after surgery, surgeons were documented by name as the surgeon performing the operation, the first assistant (who was the senior surgeon in case of tutorial assistance), and the second assistant. Thus it was taken into 
Table 1 Surgical procedures by presence of tutorial assistance and procedural characteristics

\begin{tabular}{|c|c|c|c|}
\hline Variable & $\begin{array}{l}\text { Tutorial assistance } n \\
\text { (column percent) }\end{array}$ & $\begin{array}{l}\text { Autonomous } n \\
\text { (column percent) }\end{array}$ & $\begin{array}{l}p \\
\text { Value }\end{array}$ \\
\hline Total & $2,388(100 \%)$ & $3,715(100 \%)$ & \\
\hline \multicolumn{4}{|l|}{ Age } \\
\hline$<30$ & 283 (11.9) & $258(6.9)$ & \multirow[t]{8}{*}{$<.001$} \\
\hline $30-39$ & $376(15.7)$ & $398(10.7)$ & \\
\hline $40-49$ & $346(14.5)$ & 545 (14.7) & \\
\hline $50-59$ & $322(13.5)$ & $625(16.8)$ & \\
\hline $60-69$ & 309 (12.9) & 722 (19.4) & \\
\hline $70-79$ & 348 (14.6) & 713 (19.2) & \\
\hline $80-89$ & 321 (13.4) & 385 (10.4) & \\
\hline$\geq 90$ & $83(3.5)$ & 69 (1.9) & \\
\hline \multicolumn{4}{|l|}{ Sex } \\
\hline Female & $1,101(46.1)$ & $1,854(49.9)$ & \multirow[t]{2}{*}{.004} \\
\hline Male & $1,287(53.9)$ & $1,861(50.1)$ & \\
\hline \multicolumn{4}{|l|}{ Department } \\
\hline $\begin{array}{l}\text { Visceral } \\
\text { surgery }\end{array}$ & $1,077(45.1)$ & 1,597 (43.0) & \multirow[t]{3}{*}{$<.001$} \\
\hline Traumatology & $1,121(46.9)$ & $1,317(35.4)$ & \\
\hline $\begin{array}{l}\text { Vascular } \\
\text { surgery }\end{array}$ & $190(8.0)$ & 801 (21.6) & \\
\hline \multicolumn{4}{|l|}{ ASA } \\
\hline I & $382(16.0)$ & 464 (12.5) & \multirow[t]{4}{*}{$<.001$} \\
\hline II & $1,181(49.5)$ & $1,661(44.7)$ & \\
\hline III & 746 (31.2) & $1,325(35.7)$ & \\
\hline IV or $\mathrm{V}$ & $79(3.3)$ & $265(7.1)$ & \\
\hline \multicolumn{4}{|l|}{ BMI $\left(\mathrm{kg} / \mathrm{m}^{2}\right)$} \\
\hline$<18$ & $66(2.8)$ & $124(3.3)$ & \multirow[t]{5}{*}{$<.001$} \\
\hline$<25$ & $983(41.2)$ & $1,588(42.8)$ & \\
\hline$<30$ & 637 (26.7) & $1,070(28.8)$ & \\
\hline$\geq 30$ & $290(12.1)$ & 438 (11.8) & \\
\hline Missing & $412(17.2)$ & 495 (13.3) & \\
\hline \multicolumn{4}{|l|}{ Diabetes } \\
\hline No & $2,172(90.9)$ & $3,350(90.2)$ & \multirow[t]{2}{*}{.311} \\
\hline Yes & $216(9.1)$ & $365(9.8)$ & \\
\hline \multicolumn{4}{|c|}{ Immunosuppression } \\
\hline No & $2,324(97.3)$ & $3,547(95.5)$ & \multirow[t]{3}{*}{$<.001$} \\
\hline Yes & $57(2.4)$ & $161(4.3)$ & \\
\hline Missing & $7(0.3)$ & $7(0.2)$ & \\
\hline \multicolumn{4}{|l|}{ Leukocytes $(\mu \mathrm{l})$} \\
\hline$<3,500$ & $48(2.0)$ & $113(3.0)$ & \multirow[t]{4}{*}{$<.001$} \\
\hline $3,500-10,000$ & $1,315(55.1)$ & $2,243(60.4)$ & \\
\hline$\geq 10,000$ & 849 (35.5) & 1,135 (30.6) & \\
\hline Missing & $176(7.4)$ & $224(6.0)$ & \\
\hline \multicolumn{4}{|l|}{ Tobacco } \\
\hline Never & 1,239 (51.9) & 1,991 (53.6) & \multirow[t]{3}{*}{.319} \\
\hline $\begin{array}{r}\text { Previous/ } \\
\text { ongoing }\end{array}$ & $1,032(43.2)$ & $1,533(41.3)$ & \\
\hline Missing & $117(4.9)$ & $191(5.1)$ & \\
\hline
\end{tabular}

Table 1 continued

\begin{tabular}{|c|c|c|c|}
\hline Variable & $\begin{array}{l}\text { Tutorial assistance } n \\
\text { (column percent) }\end{array}$ & $\begin{array}{l}\text { Autonomous } n \\
\text { (column percent) }\end{array}$ & $\begin{array}{l}p \\
\text { Value }\end{array}$ \\
\hline \multicolumn{4}{|c|}{ Antimicrobial prophylaxis } \\
\hline Yes & $1,722(72.1)$ & $2,774(74.7)$ & .027 \\
\hline No & $666(27.9)$ & $941(25.3)$ & \\
\hline \multicolumn{4}{|l|}{ Wound class } \\
\hline Clean & $1,398(58.5)$ & $2,307(62.1)$ & $<.001$ \\
\hline $\begin{array}{l}\text { Clean- } \\
\text { contaminated }\end{array}$ & $358(15.0)$ & $637(17.1)$ & \\
\hline Contaminated & $313(13.1)$ & $422(11.4)$ & \\
\hline Dirty-infected & $319(13.4)$ & $349(9.4)$ & \\
\hline \multicolumn{4}{|l|}{ T-time exceeded ${ }^{\mathrm{a}}$} \\
\hline Yes & $425(17.8)$ & 775 (20.9) & .006 \\
\hline No & $1,962(82.1)$ & $2,940(79.1)$ & \\
\hline Missing & $1(<0.1)$ & $0(0.0)$ & \\
\hline \multicolumn{4}{|c|}{ Other pre-existing infections } \\
\hline Yes & $259(10.9)$ & $473(12.7)$ & .027 \\
\hline No & $2,129(89.1)$ & $23,242(87.3)$ & \\
\hline \multicolumn{4}{|l|}{ Insurance } \\
\hline Private & $147(6.2)$ & $1,684(45.3)$ & $<.001$ \\
\hline Basic & $2,241(93.8)$ & $2,030(54.6)$ & \\
\hline Missing & $0(0.0)$ & $1(<0.1)$ & \\
\hline
\end{tabular}

ASA American Society of Anesthesiologists, BMI body mass index

a $T$-time 75 th percentile time as defined in the NNIS system [7]

account who actually performed the surgery and not who was assigned to do so. Later, all interventions were earmarked for the "tutorial training" or "autonomously performed surgery" group by an associate professor who performed a detailed review of the expertise and training/ experience of all surgical ward physicians. Residents prospectively screened all patients for any possible postoperative complications, including infectious processes such as SSI. They identified complications, documented treatment at discharge, and entered the information on a predesigned follow-up form. Each of these forms was crosschecked at the time of the patient's discharge by a consultant. All of the patients' charts were reviewed by a member of our study group to collect the information and to further screen for SSI that were not mentioned on the predesigned form. Suspected or known SSI patients then underwent full chart review by a board-certified infectious disease specialist. All the hospital stay data were entered on an electronically readable case report form (Cardiff TELEForm Desktop V 8.0, 2002, Verity Incorporated, Sunnyvale, CA), and the completed forms were cross-checked by a research team member.

In addition, patients were assessed for SSI after discharge. The first of the various assessment methods used was outpatient chart review: most of the patients operated 
on by the traumatology division were monitored clinically and radiologically as outpatients after discharge. The second was a questionnaire sent to patients' primary care physicians, who routinely monitored surgical wounds and removed sutures. When no reply was received, up to two reminders were mailed. Visiting research team nurses also offered primary care doctors assistance in completing the forms on the basis of their patient records. Finally, the 17\% of the patients for whom no follow-up was available were surveyed by phone to complete the missing information. Where doubts arose respecting the quality of the information furnished by these patients, they were excluded. A different data sheet was used for the outpatient monitoring. Here also, all instances of SSI were validated by the hospital hygiene and epidemiology ward, which reviewed all the relevant records. Primary care physicians and/or patients were contacted for additional information during the validation process wherever necessary. The inpatient and outpatient monitoring forms were then scanned and the data cleaned for mismatches and exported to an Excel file (Windows Microsoft Excel 2003, Microsoft Corporation, Redmond, WA).

\section{Statistical analysis}

In descriptive analyses we described categorical variables by providing frequency and percentages. To compare categorical characteristics between procedures with and without SSI we calculated the chi square statistics and the corresponding $p$ value for the null hypothesis of no association. The same procedure was followed for the univariable comparison of surgeries with and without tutorial assistance. All $p$ values were two-sided, and statistical significance was defined as $p<0.05$.

Multivariable logistic regression models were fitted to the data to take account of potentially confounding factors, while odds ratios and $95 \%$ confidence intervals were used to describe the relationship between the odds of contracting an SSI and the characteristics included in the analysis. For characteristics with several possible values, such as the ASA score, indicator variables were constructed for each separate value and entered in the models, omitting the indicator variable for the control group.

In an additional sensitivity analysis we matched procedures with an SSI to procedures without an SSI for the same type of surgical intervention, same ASA score and same wound class. In this matched case-control set we then performed an analysis using conditional logistic regression which accounts for the matching.

All the variables listed in Table 1 except surgeon experience were included in this analysis. Stata software (Stata Statistical Software: Release 9.2; Stata Corporation, College Station, TX) was used to analyze the data.

\section{Results}

General characteristics

Of the 6,540 interventions performed between 1 January 2000 and 31 December 2001, in-hospital data were not available for 257 interventions. Because the information on the surgeon's experience was insufficient and/or there was no record of whether surgery had been performed autonomously or with tutorial assistance, another 180 interventions also had to be excluded. Therefore, 6,103 (93.3\%) interventions were analyzed.

A long-term follow-up data set was built for 5,557 of the 6,103 interventions $(91.1 \%)$. In 83.3\% $(4,629 / 5,557)$ cases, follow-up was performed by a physician, whereas in $16.7 \%$ $(928 / 5,557)$ of the cases, patients were contacted directly by telephone.

The overall mortality rate for the 6,103 interventions was $3.7 \% \quad(n=225)$. In $52 \%$ of the interventions $(n=3,148)$ patients were male; in $48 \%(n=2,955)$, female. Mean patient age was 57 years $( \pm 19.4$; range $7-$ 103 years). In $14 \%(n=846)$ of the procedures the patients' ASA score was I; in $46 \%(n=2,842)$, ASA II; in $34 \%(n=2,071)$, ASA III; and in $6 \%(n=344)$, ASA IV or V. Antimicrobial prophylaxis was administered to 4,496 (74\%) patients. Overall, $61 \%(n=3,705)$ of the wounds were class I; $16 \%(n=995)$, class II; $12 \%(n=735)$, class III; and $11 \%(n=668)$, class IV.

Of the 6,103 interventions, 2,229 (36.5\%) were performed by residents; 2,290 (37.5\%), by fellows; and 1,584 (26.0\%), by an associate professor or the department head. Surgery was performed with tutorial assistance in $39.1 \%$ of the cases $(n=2,388)$ and autonomously in $60.9 \%$ $(n=3,715)$. Table 1 gives an overview of the variables studied, and Table 2 lists the types of interventions performed and the breakdown between tutorial assistance and autonomously performed surgery.

Surgical site infections

The overall rate of SSI was $4.75 \%(n=290)$. Of these 290 SSI, $29.7 \%(n=86)$ were recorded as superficial; $29.7 \%$ $(n=86)$, as deep; and $40.6 \%(n=118)$, as organ/space. The median hospital stay was 9 days (with an interquartile range of 5-16 days). Of the SSI recorded, 64\% $(n=186)$ were diagnosed during the period of hospitalization and $36 \%(n=104)$ developed after discharge.

Table 3 gives an overview of the SSI rate for the variables analyzed. Univariable analysis identified the following variables associated with an increased odds of SSI: age, vascular procedure, ASA classification, diabetes, high preoperative leukocyte count, past or present smoking, wound classification, pre-existing infections other than 
Table 2 Interventions performed: breakdown by tutorial assistance and autonomous surgery

\begin{tabular}{|c|c|c|}
\hline Intervention & $\begin{array}{l}\text { Tutorial assistance } n \\
\text { (row percent) }\end{array}$ & $\begin{array}{l}\text { Autonomous } n \\
\text { (row percent) }\end{array}$ \\
\hline Total & $2,388(39.13 \%)$ & $3,715(60.87 \%)$ \\
\hline \multicolumn{3}{|l|}{ Visceral surgery } \\
\hline Upper GI & $36(26.5)$ & $100(73.5)$ \\
\hline Lower GI & $225(38.9)$ & $354(61.1)$ \\
\hline Proctology & $70(48.6)$ & $74(51.4)$ \\
\hline $\begin{array}{l}\text { Hepatobiliary and } \\
\text { pancreatic }\end{array}$ & $137(46.0)$ & $161(54.0)$ \\
\hline Endocrine & $46(19.9)$ & $185(80.1)$ \\
\hline Hernia repair & $248(58.2)$ & $178(41.8)$ \\
\hline Others & $134(23.3)$ & $441(76.7)$ \\
\hline \multicolumn{3}{|l|}{ Vascular surgery } \\
\hline Aorta or carotids & $14(13.9)$ & $87(86.1)$ \\
\hline Peripheral arterial & $55(14.7)$ & $320(85.3)$ \\
\hline $\begin{array}{l}\text { Venous, shunts, } \\
\text { ports }\end{array}$ & $62(20.3)$ & $244(79.7)$ \\
\hline \multicolumn{3}{|l|}{ Traumatology } \\
\hline Osteosynthesis & $604(49.2)$ & $623(50.8)$ \\
\hline Prosthesis & $77(54.6)$ & $64(45.4)$ \\
\hline $\begin{array}{l}\text { Soft tissue } \\
\quad \text { interventions }\end{array}$ & $444(54.5)$ & $370(45.5)$ \\
\hline Others & $236(31.5)$ & $514(68.5)$ \\
\hline
\end{tabular}

SSI, and exceeded T-time (operation time in excess of the 75th percentile of duration of type-specific surgery) [7].

Multivariable analysis identified the following risk factors $(p<0.05)$ : age $80-89$ years $(p=0.029)$, body mass index $(\mathrm{BMI}) \geq 30 \mathrm{~kg} / \mathrm{m}^{2} \quad(p=0.018)$, past or present smoking $(p=0.033)$, contaminated wounds $(p<0.001)$ and clean-contaminated ( $p=0.003$ ) wounds, pre-existing infections other than SSI ( $p=0.009)$, and exceeded T-time $(p<0.001)$ (Table 4 , overall variable $p$ values). Contrary to the univariable analysis findings, in multivariable analysis vascular procedure, ASA classification, diabetes, and high preoperative leukocyte count were not identified as significant risk factors.

Teaching assistance versus autonomously performed interventions

The SSI rate for the 3,715 interventions autonomously performed by board-certified surgeons was $5.36 \%$ $(n=199)$. In the tutorial assistance group, with 2,388 interventions, the SSI rate was only $3.81 \%(n=91)$. In univariable analysis this difference was significant $(p=0.006, \quad \mathrm{OR}=0.70, \quad 95 \% \quad \mathrm{CI}=0.543-0.902)$, but multivariable analyses failed to show any significant difference in the SSI rate between tutorial assistance, $(p$ value $=0.163 ;$ OR $=0.82 ; 95 \% \mathrm{CI}=0.62-1.09)$ and
Table 3 Univariable analysis: number of surgical procedures, number and percentage of surgical site infections (SSI) by variable

\begin{tabular}{|c|c|c|c|c|}
\hline Variable & $\begin{array}{l}\text { Number of } \\
\text { surgical } \\
\text { procedures }\end{array}$ & $\begin{array}{l}\text { Number } \\
\text { of SSI }\end{array}$ & $\begin{array}{l}\% \\
\text { SSI }\end{array}$ & $\begin{array}{l}p \text { Value } \\
\text { (univariable } \\
\text { analysis) }\end{array}$ \\
\hline Total & 6,103 & 290 & 4.75 & - \\
\hline \multicolumn{5}{|l|}{ Age (years) } \\
\hline$<30$ & 541 & 15 & 2.77 & 0.023 \\
\hline $30-39$ & 774 & 23 & 2.97 & \\
\hline $40-49$ & 891 & 38 & 4.26 & \\
\hline $50-59$ & 947 & 48 & 5.07 & \\
\hline $60-69$ & 1,031 & 57 & 5.53 & \\
\hline $70-79$ & 1,061 & 58 & 5.47 & \\
\hline $80-89$ & 706 & 43 & 6.09 & \\
\hline$\geq 90$ & 152 & 8 & 5.26 & \\
\hline \multicolumn{5}{|l|}{ Sex } \\
\hline Female & 2,955 & 138 & 4.67 & 0.771 \\
\hline Male & 3,148 & 152 & 4.83 & \\
\hline \multicolumn{5}{|l|}{ Department } \\
\hline $\begin{array}{l}\text { Visceral } \\
\text { surgery }\end{array}$ & $2,, 674$ & 145 & 5.42 & $<0.001$ \\
\hline Traumatology & 2,438 & 80 & 3.28 & \\
\hline $\begin{array}{l}\text { Vascular } \\
\text { surgery }\end{array}$ & 991 & 65 & 6.56 & \\
\hline \multicolumn{5}{|l|}{ ASA score } \\
\hline I & 846 & 20 & 2.36 & $<0.001$ \\
\hline II & 2,842 & 108 & 3.80 & \\
\hline III & 2,071 & 131 & 6.33 & \\
\hline IV or V & 344 & 31 & 9.01 & \\
\hline \multicolumn{5}{|l|}{ BMI $\left(\mathrm{kg} / \mathrm{m}^{2}\right)$} \\
\hline$<18$ & 190 & 10 & 5.26 & 0.059 \\
\hline$<25$ & 2,571 & 106 & 4.12 & \\
\hline$<30$ & 1,707 & 85 & 4.98 & \\
\hline$\geq 30$ & 728 & 49 & 6.73 & \\
\hline Missing & 907 & 40 & 4.41 & \\
\hline \multicolumn{5}{|l|}{ Diabetes } \\
\hline No & 5,522 & 250 & 4.53 & 0.011 \\
\hline Yes & 581 & 40 & 6.88 & \\
\hline \multicolumn{5}{|c|}{ Immunosuppression } \\
\hline No & 5,871 & 273 & 4.65 & 0.071 \\
\hline Yes & 218 & 17 & 7.80 & \\
\hline Missing & 14 & 0 & 0 & \\
\hline \multicolumn{5}{|l|}{ Leukocytes $(\mu \mathrm{l})$} \\
\hline$<3,500$ & 161 & 4 & 2.48 & 0.001 \\
\hline $3,500-10,000$ & 3,558 & 160 & 4.50 & \\
\hline$\geq 10,000$ & 1,984 & 119 & 6.00 & \\
\hline Missing & 400 & 7 & 1.75 & \\
\hline \multicolumn{5}{|l|}{ Tobacco } \\
\hline Never & 3,230 & 135 & 4.18 & 0.024 \\
\hline $\begin{array}{l}\text { Previous/ } \\
\text { ongoing }\end{array}$ & 2,565 & 144 & 5.61 & \\
\hline Missing & 308 & 11 & 3.57 & \\
\hline
\end{tabular}


Table 3 continued

\begin{tabular}{|c|c|c|c|c|}
\hline Variable & $\begin{array}{l}\text { Number of } \\
\text { surgical } \\
\text { procedures }\end{array}$ & $\begin{array}{l}\text { Number } \\
\text { of SSI }\end{array}$ & $\begin{array}{l}\% \\
\text { SSI }\end{array}$ & $\begin{array}{l}p \text { Value } \\
\text { (univariable } \\
\text { analysis) }\end{array}$ \\
\hline \multicolumn{5}{|c|}{ Antimicrobial prophylaxis } \\
\hline Yes & 4,496 & 222 & 4.94 & 0.253 \\
\hline No & 1,607 & 68 & 4.23 & \\
\hline \multicolumn{5}{|l|}{ Wound class } \\
\hline Clean & 3,705 & 126 & 3.40 & $<0.001$ \\
\hline $\begin{array}{l}\text { Clean- } \\
\text { contaminated }\end{array}$ & 995 & 66 & 6.63 & \\
\hline Contaminated & 735 & 61 & 8.30 & \\
\hline Dirty-infected & 668 & 37 & 5.54 & \\
\hline \multicolumn{5}{|l|}{ T-time exceeded ${ }^{\mathrm{a}}$} \\
\hline Yes & 1,200 & 98 & 8.17 & $<0.001$ \\
\hline No & 4,902 & 192 & 3.92 & \\
\hline Missing & 1 & 0 & 0 & \\
\hline \multicolumn{5}{|c|}{ Other pre-existing infections } \\
\hline Yes & 732 & 62 & 8.47 & $<0.001$ \\
\hline No & 5,371 & 228 & 4.25 & \\
\hline \multicolumn{5}{|l|}{ Insurance } \\
\hline Private & 1,831 & 86 & 4.70 & 0.967 \\
\hline Basic & 4,271 & 204 & 4.78 & \\
\hline Missing & 1 & 0 & 0 & \\
\hline \multicolumn{5}{|l|}{ Surgeon } \\
\hline Resident & 2,229 & 71 & 3.19 & $<0.001$ \\
\hline Fellow & 2,290 & 132 & 5.76 & \\
\hline $\begin{array}{l}\text { Associate } \\
\text { prof./head } \\
\text { department }\end{array}$ & 1,584 & 87 & 5.49 & \\
\hline \multicolumn{5}{|l|}{ Tutorial assistance } \\
\hline Yes & 2,388 & 91 & 3.81 & 0.006 \\
\hline No & 3,715 & 199 & 5.36 & \\
\hline
\end{tabular}

a -time 75th percentile time as defined in the NNIS system [7]

autonomously performed interventions (Table 4, Fig. 1). Multivariable analysis was supplemented by including the 14 different anatomical areas of interventions listed in Table 2 as additional variables. The results found with this analysis were similar to the above, with a $p$ value of 0.170 , an $\mathrm{OR}=0.82$, and a $95 \% \mathrm{CI}=0.61-1.09$. Furthermore, we assessed whether there is evidence for differences in this association across departments by incorporating effect modification terms into the multivariable logistic regression model and tested for effect modification, calculating the likelihood ratio test. We found no evidence for effect modification $(p=0.19)$.

We obtained very similar results in our sensitivity analysis using the approach of matching cases to controls and to perform an analysis using conditional logistic regression. We obtained an odds ratio of 0.85 for the
Table 4 Multivariable analysis: odds-ratio and 95\% confidence intervals for the association of surgical site infection (SSI) by variable

\begin{tabular}{llll}
\hline Variable category & Odds ratio & $\begin{array}{l}95 \% \text { Confidence } \\
\text { interval }\end{array}$ & $\begin{array}{l}p \\
\text { Value }\end{array}$
\end{tabular}

Age

$<30$

Reference

0.199

30-39 group

$40-49$

1.00

$0.51-2.0$

$50-59$

1.38

$0.74-2.6$

60-69

1.64

$0.88-3.0$

$70-79$

1.57

$0.85-2.9$

$80-89$

1.44

0.77-2. 7

$\geq 90$

2.07

1.08-4.0

2.34

0.92-6.0

Sex

Female

1.04

$0.80-1.34$

Male

Reference group

Department

Visceral

Reference

0.081

Traumatology group

Vascular

0.77

0.57-1.05

0.83-1.66

ASA score

I

Reference

0.321

II group

0.62-1.72

III

1.28

$0.75-2.2$

IV or V

1.55

BMI $\left(\mathrm{kg} / \mathrm{m}^{2}\right)$

18-25

Reference

0.80-3.0

group

$\begin{array}{ll}<18 & 0.99\end{array}$

$0.50-2.0$

$>25$

1.20

$0.89-1.62$

$\geq 30$

1.56

$1.08-2.2$

Diabetes

$\begin{array}{lll}\text { Yes } & 1.06 & 0.73-1.54 \\ \text { No } & \begin{array}{l}\text { Reference } \\ \text { group }\end{array}\end{array}$

$0.81-2.3$

$\begin{array}{ll}\text { Yes } & 1.38 \\ \text { No } & \text { Reference } \\ & \text { group }\end{array}$

Leukocytes $(\mu \mathrm{l})$

$3,500-10,000$

Reference

$<3,500$

group

$>10,000 \quad 1.22$

0.18-1.40

0.94-1.59

Tobacco

$\begin{array}{lll}\text { Yes } & 1.34 & 1.03-1.75 \\ \text { No } & \begin{array}{l}\text { Reference } \\ \text { group }\end{array}\end{array}$

0.100

0.121 .778 
Table 4 continued

\begin{tabular}{|c|c|c|c|}
\hline Variable category & Odds ratio & $\begin{array}{l}\text { 95\% Confidence } \\
\text { interval }\end{array}$ & $\begin{array}{l}p \\
\text { Value }\end{array}$ \\
\hline \multicolumn{4}{|c|}{ Antimicrobial prophylaxis } \\
\hline No & 0.85 & $0.63-1.15$ & .295 \\
\hline Yes & $\begin{array}{l}\text { Reference } \\
\text { group }\end{array}$ & & \\
\hline \multicolumn{4}{|l|}{ Wound class } \\
\hline Clean & $\begin{array}{l}\text { Reference } \\
\text { group }\end{array}$ & & $<0.001$ \\
\hline $\begin{array}{l}\text { Clean- } \\
\text { contaminated }\end{array}$ & 1.66 & $1.19-2.3$ & \\
\hline Contaminated & 2.20 & $1.55-3.1$ & \\
\hline Dirty-infected & 1.53 & $0.99-2.3$ & \\
\hline \multicolumn{4}{|l|}{ T-time exceeded ${ }^{\mathrm{a}}$} \\
\hline Yes & 2.00 & $1.53-2.6$ & $<.001$ \\
\hline No & $\begin{array}{l}\text { Reference } \\
\text { group }\end{array}$ & & \\
\hline \multicolumn{4}{|c|}{ Other pre-existing infections } \\
\hline Yes & 1.53 & $1.112-2.104$ & .009 \\
\hline No & $\begin{array}{l}\text { Reference } \\
\text { group }\end{array}$ & & \\
\hline \multicolumn{4}{|l|}{ Insurance } \\
\hline Private & 1.02 & $0.76-1.36$ & .912 \\
\hline Basic & $\begin{array}{l}\text { Reference } \\
\text { group }\end{array}$ & & \\
\hline \multicolumn{4}{|l|}{ Tutorial assistance } \\
\hline Tutorial & 0.82 & $0.62-1.09$ & .163 \\
\hline Autonomous & 1.0 & & \\
\hline
\end{tabular}

Results were derived from a multivariable logistic regression model that included all of the listed variables and duration of surgery in minutes

The number of surgical procedures as well as the number and percentage of surgical site infections (SSI) per variable are given in Table 3

a $T$-time 75 th percentile time as defined in the NNIS system [7]

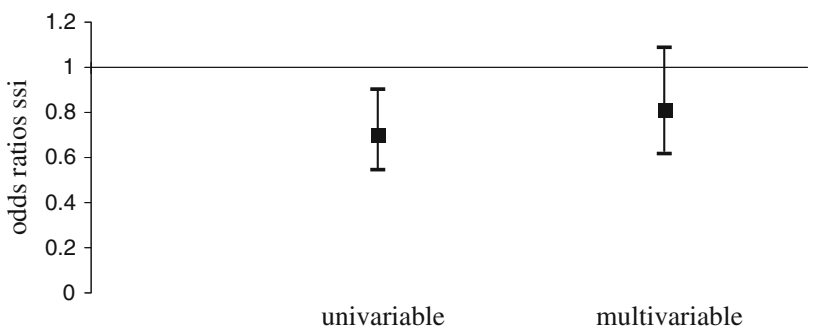

Fig. 1 Odds ratio for SSI in surgery involving tutorial assistance compared to surgery performed autonomously (control group) in univariable $(p=0.006)$ and multivariable analysis $(p=0.163)$

association of tutorial assistance (versus autonomously performed interventions) with SSI (95\% CI $=0.61-1.18$; $p$ value $=0.328$ )

\section{Discussion}

Today, surgical training can be delivered by a number of techniques, including box-models and virtual reality simulation [2, 8-11]. Nevertheless, these training methods, which must be viewed as supplements to the traditional apprenticeship model, cannot replace tutorial assistance in the operating room. Even so, concerns have been raised about the possible impact of tutorial assistance on the rate of complications such as SSI, which would be detrimental to patients. This study clearly shows that teaching assistance does not necessarily lead to high SSI rates if supervision is guaranteed and the selection of patients is in keeping with the surgical trainee's expertise.

One of the most common postoperative complications is SSI. A survey conducted in four university hospitals in Switzerland found SSI to be the most frequent nosocomial infection after surgery [12]. The risk factors for contracting SSI, of which there are many, may be patient-related or surgery-related [5, 13]. Among the patient-related factors are age, nutritional status, obesity, diabetes mellitus, tobacco abuse, and immunosuppression, whereas preoperative surgical scrub, duration of operation, administration and timing of antibiotic prophylaxis [14], implantation of foreign material, surgical drains and surgical techniques, including asepsis, hemostasis, atraumatic technique and obliteration of dead spaces, constitute surgery-related risk factors. The Centers for Disease Control and Prevention (CDC) NNIS Web site regularly publishes multicenter data on SSI rates [15]. The pooled mean SSI rates by operative procedure and risk index category published in its latest report, which covers the period running from January 1992 through June 2004, ranged from $0.15 \%$ (other endocrine system, risk index category 0 ) to $11.25 \%$ (colon, risk index category 3) [16]. For herniorrhaphy for instance, the pooled mean SSI rate was $0.81 \%$ for risk index category 0 [16]. A 10 -year wound infection surveillance program conducted prior to this period found SSI rates to be $2.5 \%$ overall, $1.4 \%$ for class I $(63.3 \%), 5.4 \%$ for class II $(26.4 \%)$, and $8.4 \%$ for class III $(10.3 \%)$ wounds [17]. In the present study, the overall SSI rate was higher. This may be explained by the different factors considered in our study. For example, Olson et al. [17] took into account only the first 30 postoperative days in their assessment of SSI. According to the CDC definition however, SSI should be considered as a complication occurring up to one year of an operation involving an implant. Importantly, the report by Olsen et al. did not include class IV wounds but involved more class I and class II wounds, accounting for a lower overall SSI rate. Moreover, our data acquisition is a combination of prospective data entry, retrospective chart review, and peer review by the hospital epidemiology staff. The combination of active surveillance by two independent 
departments, complemented by vigorous postdischarge surveillance, explains the higher infection rates. In addition, a tertiary care center in general has higher infection rates due to the case-mix that is very difficult to control for by statistical methods. Therefore we strongly believe that our SSI identification rate is as complete as possible, resulting in an incidence higher than those reported by other authors.

According to the data collected for the present survey, a high proportion $(36 \%)$ of SSI were diagnosed after discharge. Therefore, follow-up for surgical patients and postdischarge SSI monitoring are crucial [18].

Over 25 years ago, a negative correlation was shown to exist between a surgeon's case volume and the respective SSI rate after appendectomy, herniorrhaphy, cholecystectomy, colon resection, and abdominal hysterectomy [19]. This same indirect relationship has recently been found for coronary artery bypass graft surgery [20].

Nonetheless, very few studies, and all with widely varying designs, have been conducted on the effect of the surgeon's experience on the rate of SSI. Wurtz et al. explored the possible difference in the rates of class I SSI for "new surgeons" having finished training within 6 months of joining the staff, "new-experienced surgeons" having finished training more than 6 months prior to joining the staff, and "experienced surgeons" on the staff for at least 5 years [21]. They found "new surgeons" to have higher SSI rates than their more experienced colleagues in two surgical subspecialities with infection-prone procedures and to take longer in the operating room despite the lack of any significant difference in patients' average ASA score. The cumulative number of cases and the SSI rate were negatively correlated. In cesarean sections, for example, a resident acting as a lead surgeon was found to be an independent risk factor for endometritis [22]. The rate of postoperative endometritis for attending physicians, chief residents, and residents was $6 \%, 12 \%$, and $24 \%$, respectively. In mastectomies, by contrast, surgical experience (67 operations performed by registrars, 58 by senior registrars, 21 by part-time consultants, and 18 by professors) was found to have no significant impact on complications [23]. No differences were observed in the percentage of infection, seromas requiring aspiration, wound breakdown, length of hospital stay, or cost.

In a prospective randomized study of the infection rate at the vena saphena harvesting site for coronary artery bypass grafting, no difference was found when an additional subcutaneous suture line was made by a single experienced physical assistant. The infection rate recorded for the control group, however, which consisted a number of surgical residents, was significantly higher [24], although it is not clear from the report whether the residents were supervised. In first ventriculoperitoneal shunt implantations performed between 1989 and 2001, the infection rate was significantly higher in patients treated by less experienced surgeons than in those treated by more experienced surgeons [25].

In the present study multivariable analysis showed significantly higher surgical site infection rates in the presence of risk factors such as age, pre-existing infections other than SSI, clean-contaminated or contaminated wounds, and BMI $\geq 30 \mathrm{~kg} / \mathrm{m}^{2}$. None of these results is unexpected, for they are patient-related. Exceeded T-time, a surgeondependent risk factor, was also identified as a risk factor in both univariable and multivariable analysis. The significant difference in SSI rate between visceral surgery, vascular surgery, and traumatology in univariable analysis was no longer significant in multivariable analysis. This reflects the difference in contributing risk factors for SSI. In traumatology, most of the wounds are clean and therefore at lower risk for SSI. In contrast, patients with arteriopathy are likely to present some of the risk factors such as high ASA class, diabetes mellitus, tobacco use, or obesity, and are therefore at higher risk for SSI.

The present study is subject to certain limitations. First, it is not a randomized, controlled trial. As Tables 1 and 2 show, patient characteristics and types of intervention were not equally distributed between the tutorial assistance and autonomous surgery groups. Rather, the distribution denotes the careful and individual selection of patients and the types of intervention in which tutorial assistance was regarded to be feasible. Multivariable analysis including 13 patient and procedural characteristics was used to take this difference into consideration when interpreting the data. However, because of the observational nature of this study, residual confounding by characteristics not recorded and therefore not accounted for in the analysis cannot be excluded.

Second, long-term outpatient follow-up data were not recorded prospectively, although information was collected from a very large sample with a high rate of outpatient follow-up data on the post-discharge development of SSI.

\section{Conclusions}

In carefully selected interventions, teaching assistance under supervision of a fully trained surgeon does not result in a higher rate of SSI. While other forms of training are useful, in-theater tutorial assistance continues to be the mainstay of surgical education.

Acknowledgments This research was funded by the Department of General Surgery, Basel University Hospital, and Freiwillige Akademische Gesellschaft Basel, Switzerland. The authors thank Martin Bolli, Silvia Chocomeli, Marc Dangel, Philipp Füglistaler, Marco 
Grementieri, Andrea Imgraben, and Alexandra Schifferli for their assistance in data collection and scanning.

\section{References}

1. Halsted WS (1904) The training of the surgeon. Bull Johns Hopkins Hosp 15:267-275

2. Sutherland LM, Middleton PF, Anthony A et al (2006) Surgical simulation. A systematic review. Ann Surg 243:291-300

3. Garner JS (1986) CDC guidelines for prevention of surgical wound infections, 1985. Supersedes guideline for prevention of surgical wound infections published in 1982. (Originally published, November 1985). Revised. Infect Control 7:193-200

4. Simmons BP (1982) CDC guidelines on infection control. Infect Control 3(2 Suppl):187-196

5. Mangram AJ, Horan TC, Pearson ML et al (1999) Guideline for prevention of surgical site infection, 1999. Centers for Disease Control and Prevention (CDC) Hospital Infection Control Practices Advisory Committee. Am J Infect Control 27:97-132

6. Horan TC, Gaynes RP, Martone WJ et al (1992) CDC definitions of nosocomial surgical site infections, 1992: a modification of CDC definitions of surgical wound infections. Infect Control Hosp Epidemiol 13:606-608

7. Culver DH, Horan TC, Gaynes RP et al (1991) NNIS Surveillance System. Surgical wound infection rates by wound class, operative procedure, and patient risk index. Am J Med 91:S152S157

8. Dutta S, Gaba D, Krummel TM (2006) To simulate or not to simulate. What is the question? Ann Surg 243:301-303

9. Seymour NE, Rotnes JS (2006) Challenges to the development of complex virtual reality surgical simulations. Surg Endosc 20:1774-1777

10. Seymour NE, Gallagher AG, Roman SA et al (2002) Virtual reality training improves operating room performance. Ann Surg 236:458-464

11. Grantcharov TP, Kristiansen VB, Bendix J et al (2004) Randomized clinical trial of virtual reality simulation for laparoscopic skills training. Br J Surg 91:146-150

12. Pittet D, Harbarth S, Ruef $C$ et al (1999) Prevalence and risk factors for nosocomial infections in four university hospitals in Switzerland. Infect Control Hosp Epidemiol 20:37-42
13. Gastmeier P, Brandt C, Sohr D et al (2006) [Postoperative Wundinfektionen. Der Chirurg als Täter oder Opfer?]. Chirurg 6:506-511

14. Classen DC, Evans RS, Pestotnik SL et al (1992) The timing of prophylactic administration of antibiotics and the risk of surgicalwound infection. N Engl J Med 326:281-286

15. National Nosocomial Infections Surveillance System (NNIS) (2009) http://www.cdc.gov/ncidod/dhqp/nnis_pubs.html. Accessed 23 March 2009

16. National Nosocomial Infections Surveillance System (NNIS) (2004) National nosocomial infection surveillance system report, data summary from January 1992 through June 2004, issued October 2004. Am J Infect Control 32:470-485

17. Olson MM, Lee JT Jr (1990) Continuous, 10-year wound infection surveillance. Results, advantages, and unanswered questions. Arch Surg 125:794-803

18. Oliveira AC, Carvalho DV (2004) Postdischarge surveillance: the impact on surgical site infection incidence in a Brazilian university hospital. Am J Infect Control 32:358-361

19. Farber BF, Kaiser DL, Wenzel RP (1981) Relation between surgical volume and incidence of postoperative wound infection. N Engl J Med 305:200-204

20. Wu SC, Chen CC, Ng YY et al (2006) The relationship between surgical site infection and volume of coronary artery bypass graft surgeries: Taiwan experience. Infect Control Hosp Epidemiol 27:308-311

21. Wurtz R, Wittrock B, Lavin MA et al (2001) Do new surgeons have higher surgical-site infection rates? Infect Control Hosp Epidemiol 22:375-377

22. Miller PJ, Searcy MA, Kaiser DL et al (1987) The relationship between surgeon experience and endometritis after cesarean section. Surg Gynecol Obstet 165:535-539

23. Funnell IC, Crowe PJ, Dent DM (1992) Does surgical experience influence mastectomy complications? Ann R Coll Surg Engl 74:178-180

24. Stenvik M, Tjomsland O, Lien S et al (2006) Effect of subcutaneous suture line and surgical technique on wound infection after saphenectomy in coronary artery bypass grafting: a prospective randomised study. Scand Cardiovasc J 40:234-237

25. Cochrane DD, Kestle JR (2003) The influence of surgical operative experience on the duration of first ventriculoperitoneal shunt function and infection. Pediatr Neurosurg 38:295-301 